\title{
Chemical Reaction based Optimal Reactive Power Flow
}

\author{
G.K. Moorthy \\ Research Scholar \\ Department of Electrical \\ Engineering \\ Annamalai University \\ Tamil Nadu, India
}

\author{
R.K. Santhi \\ Professor of Electrical \\ Engineering \\ Annamalai University \\ Tamil Nadu, India
}

\author{
S.M. Alamelu, PhD \\ Professor of Electrical \\ Engineering \\ Pondicherry Engineering \\ College \\ Puducherry, India
}

\begin{abstract}
The optimal reactive power flow (ORPF) helps to effectively utilize the existing reactive power sources for minimizing the network loss. The chemical reaction optimization (CRO), inspired from the interactions of molecules in a chemical reaction to reach a low energy stable state and searches for optimal solution through reactions involving the on-wall ineffective collisions, decomposition, inter-molecular ineffective collision and synthesis. This paper attempts to obtain global best solution of ORPF using CRO. The results of IEEE 30 bus system are presented to demonstrate its performance.
\end{abstract}

\section{Keywords}

Optimal reactive power flow, chemical reaction optimization

\section{NOMENCLATURE}

\begin{tabular}{|c|c|}
\hline BBO & biogeography based optimization \\
\hline CRO & chemical reaction optimization \\
\hline $\mathrm{DE}$ & differential evolution \\
\hline ORPF & optimal reactive power flow \\
\hline GA & genetic algorithm \\
\hline$G_{i j}+j$ & $\begin{array}{l}j B i j \text { Real and imaginary terms of bus admittance } \\
\text { matrix corresponding to } k \text {-th row and }-j \text {-th } \\
\text { column }\end{array}$ \\
\hline$g_{i j}$ & $\begin{array}{l}\text { Conductance of the transmission line connected } \\
\text { between buses }-i \text { and } j\end{array}$ \\
\hline$g(x, u)$ & Equality constraint \\
\hline$h(x, u)$ & Inequality constraint \\
\hline$J(x, u)$ & Objective function \\
\hline $\mathrm{KE}$ & kinetic energy \\
\hline$n c$ & Number of shunt reactive power compensators \\
\hline$n$ & Number of decision variables \\
\hline nobj & Number of objectives \\
\hline$n g$ & Number of generators \\
\hline$n t$ & Number of transformers \\
\hline $\mathrm{PE}$ & potential energy \\
\hline PM & proposed method \\
\hline
\end{tabular}

\begin{tabular}{|c|c|}
\hline$P S$ & Population size \\
\hline PSO & particle swarm optimization \\
\hline$Q_{G i}$ & Reactive power generation at bus- $i$ \\
\hline$Q_{C i}$ & $\begin{array}{l}\text { Reactive power injection by } i \text {-th shunt } \\
\text { compensator }\end{array}$ \\
\hline RPL & real power loss \\
\hline$T_{i}$ & Tap settings of $i$-th transformer \\
\hline VP & voltage profile \\
\hline$V_{i}$ & Voltage at $i$-th bus \\
\hline$V_{L i}^{\lim i t}$ & $\begin{array}{l}\text { Limit violated voltage magnitude at } i \text {-th } \\
\text { load bus }\end{array}$ \\
\hline$Q_{G i}^{\lim i t}$ & $\begin{array}{l}\text { Limit violated reactive power generation } \\
\text { at } i \text {-th PV bus }\end{array}$ \\
\hline$V_{G i}$ & Voltage magnitude at $i$-th generator bus \\
\hline$V_{L i}$ & Voltage magnitude at $i$-th load bus \\
\hline$x$ & Vector of dependant variables \\
\hline$u$ & $\begin{array}{l}\text { Vector of control or independent } \\
\text { variables }\end{array}$ \\
\hline$\lambda_{V}$ and $\lambda_{C}$ & Penalty factors \\
\hline$\omega_{i}$ & Structure of $i$-th molecule \\
\hline $\mathfrak{J}$ & ansmission lines \\
\hline$\Phi$ & ad buses \\
\hline $\mathrm{as}$ & $\begin{array}{l}\text { nerator buses superscript } \min \text { and } \\
\text { er and upper limits respectively }\end{array}$ \\
\hline
\end{tabular}

\section{INTRODUCTION}

The Optimal Reactive Power Flow (ORPF) aims to minimize the real power loss (RPL) via the optimal adjustment of the power system control variables, while at the same time satisfying various equality and inequality constraints. The equality constraints are the power flow balance equations, while the inequality constraints are the limits on the control 
variables and the operating limits of the power system dependent variables. The problem control variables comprise the generator bus voltages, the transformer tap settings, and the reactive power of shunt compensators, while the problem dependent variables contain the load bus voltages, the generator reactive powers, and the line flows. Generally ORPF problem is a large scale highly constrained nonconvex and multimodal optimization problem $[1,2]$.

Several traditional optimization techniques such as gradient method [1,2], Newton method [3], linear programming [4-7], interior point method [8] and non linear programming [9] have been applied to solve the ORPF problem. These methods have severe limitations in handling non-linear and discontinuous objectives and constraints. Besides, these classical optimization techniques involving derivatives and gradients may not be able to determine the global optimum. Thus there is a need for evolving simple and effective methods for obtaining global optimal solution for the ORPF problem.

Metaheuristic methods such as genetic algorithm (GA) [1012], evolutionary programming [13], particle swarm optimization (PSO) [14], differential evolution (DE) [15-17], seeker optimization algorithm [18] and biogeography based optimization (BBO) [19] have been recently applied in solving the ORPF problems. These algorithms have found extensive applications in solving complex optimization problems, when the classical optimization technique cannot be applied. These approaches are more likely to converge towards the global solution because they simultaneously evaluate many points in the search space and do not require assuming that the search space is differentiable or continuous.

More recently, a Chemical Reaction Optimization (CRO), a population based stochastic optimization technique inspired from the process of chemical reactions, has been suggested for solving combinatorial optimization problems in discrete domains by Lam et al. [20]. A modified version of CRO, named as real coded CRO, to handle problems in both continuous and discrete domains, has been outlined in [21]. The CRO has been applied to a variety of optimization problems [22-24] that includes economic emission load dispatch [22] and found to yield satisfactory results.

This article aims to develop a CRO based strategy for obtaining the global best solution of ORPF. The results on IEEE 30 bus system are presented to demonstrate the effectiveness of the developed strategy. The paper is divided into six sections. Section 1 presents the introduction, section 2 briefs CRO, section 3 formulates the ORPF problem, section 4 suggests the proposed solution strategy, section 5 discusses the results and section 6 concludes.

\section{CRO}

In chemical reactions, the molecules of initial reactants, possessing high-energy unstable states, undergo a sequence of collisions either with walls of the container or with other molecules, pass through some energy barriers and become final products by releasing energy. The final products generally have less energy, thereby making them more stable than the reactants. This phenomenon of driving the molecules from high-energy unstable states to low-energy stable states by chemical reaction can be related to the process of minimising the objective function value in optimization problems through adjusting the control variables. Inspired from this relation, CRO algorithm for solving multimodal optimization problems has been developed by Lam et al. [20,21]. In CRO algorithm, each solution point in the problem space is represented by a molecule, which composes several atoms and involves two kinds of energies, the potential energy $(P E)$ and the kinetic energy $(K E)$. Each molecule therefore contains a profile of several properties such as $\omega, P E$ and $K E$. The $P E$ represents the problem objective function for each solution point $\omega$ as

Minimize $P E_{i}=f\left(\omega_{i}\right)$

When the algorithm evolves, the molecules adjust their structure through a sequence of collisions among molecules to possess lower $P E$ and $K E$ and the removed energy is stored in a central energy buffer. Molecules collide either with each other or with the walls of the container, resulting in an internal change of molecules. There are four types of elementary reactions implemented in CRO, namely, on-wall ineffective collision, decomposition, inter-molecular ineffective collision, and synthesis. These reactions explore the solution space in search of optimal solution.

An initial set of molecules with size equal to $P S$ is then randomly generated in the solution space. Their initial PEs are determined by their corresponding objective function values. In each iteration, there is one elementary reaction taking place, which is probabilistically chosen by generating a random number. The molecule with lowest PE is recorded and the iterative process is continued until the stopping criterion is met. After convergence, the molecule with the lowest PE is considered as the optimal solution. The detailed pseudo code is available in Ref. [20].

\section{PROBLEM FORMULATION}

The ORPF problem is formulated as an optimization problem with several equality and inequality constraints as

Minimize

$J(x, u)=R P L=\sum_{k \in \mathfrak{I}} g_{i j}\left(\left|V_{i}\right|^{2}+\left|V_{j}\right|^{2}-2\left|V_{i}\right|\left|V_{j}\right| \cos \delta_{i j}\right)$

Subject to

$g(x, u)=0$

$h(x, u) \leq 0$

Where $x$ is the vector of dependant variables consisting of load bus voltage magnitudes, reactive power generation at generator buses and real power generation at slack bus. $u$ is the vector of control or independent variables comprising of generator bus voltage magnitudes, transformer tap settings and output of reactive shunt compensators. RPL can be calculated from the load flow solution. The equality constraints $g(x, u)$ are the sets of non-linear power flow equations that govern the power system

$$
\begin{aligned}
& P_{G i}-P_{D i}-V_{i} \sum_{j=I^{\prime}}^{n b} V_{j}\left(G_{i j} \cos \delta_{i j}+B_{i j} \sin \delta_{i j}\right)=0 \\
& Q_{G i}-Q_{D i}-V_{i} \sum_{j=I^{\prime}}^{n b} V_{j}\left(G_{i j} \sin \delta_{i j}-B_{i j} \cos \delta_{i j}\right)=0
\end{aligned}
$$


The equality constraints $h(x, u)$ represent the operating limits on reactive power generations, transformer tap settings and voltage magnitudes.

$$
\begin{gathered}
Q_{G i}^{\min } \leq Q_{G i} \leq Q_{G i}^{\max } \\
Q_{C i}^{\min } \leq Q_{C i} \leq Q_{C i}^{\max }
\end{gathered}
$$

$$
\begin{gathered}
T_{i}^{\min } \leq T_{i} \leq T_{i}^{\max } \\
V_{G i}^{\min } \leq V_{G i} \leq V_{G i}^{\max } \\
V_{L i}^{\min } \leq V_{L i} \leq V_{L i}^{\max }
\end{gathered}
$$

\section{PROPOSED METHOD}

The proposed method involves representation of problem variables and the formation of appropriate $P E$ function.

Representation of Control Variables: In CRO, a solution is represented by a molecular structure- $\omega_{i}$. In the proposed method, each molecular structure $\omega_{i}$ is defined to denote the control variables of voltage magnitude at generator buses, transformer tap positions and reactive power of shunt compensators in vector form as

$\omega_{i}=\left[V_{G 1}, V_{G 2}, \cdots, V_{G n g}, T_{1}, T_{2}, \cdots, T_{n t}, Q_{C 1}, Q_{C 2}, \cdots, Q_{C n c}\right]$

Formation of PE function: The proposed method searches for optimal solution by minimizing a $P E$ function, which is formulated from the objective function and the penalty terms representing the limit violation of the dependant variables such as reactive power generation at PV buses and voltage magnitude at load buses. The $P E$ function is built as

$$
P E=J(x, u)+\lambda_{V} \sum_{i \in \Phi}\left(V_{L i}-V_{L i}^{\lim i t}\right)^{2}+\lambda_{Q} \sum_{i \in \Omega}\left(Q_{G i}-Q_{G i}^{\lim i t}\right)^{2}
$$

Where

$$
\begin{aligned}
& V_{L i}^{\text {limit }}=\left\{\begin{array}{cc}
V_{L i}^{\min } & \text { if } V_{L i}<V_{L i}^{\min } \\
V_{L i}^{\max } & \text { if } V_{L i}>V_{L i}^{\max } \\
V_{L i} & \text { else }
\end{array}\right. \\
& Q_{G i}^{\text {limit }}= \begin{cases}Q_{G i}^{\min } & \text { if } Q_{G i}<Q_{G i}^{\min } \\
Q_{G i}^{\max } & \text { if } Q_{G i}>Q_{G i}^{\max } \\
Q_{G i} & \text { else }\end{cases}
\end{aligned}
$$

Solution Process: The population containing molecules is initialized by random values within the respective control variable limits. The ACRO search process is performed through chemical reactions involving the on-wall ineffective collisions, decomposition, inter-molecular ineffective collision and synthesis, after evaluating the $P E$ values. The molecule with lowest $\mathrm{PE}$ is recorded and the iterative process is continued till convergence. The algorithmic steps are summarized below:

1. Read the ORPF problem data

2. Choose $\mathrm{CRO}$ parameters

3. Randomly generate molecules to form the initial population and initialize $K E$ of all molecules

4. Probabilistically choose any one of the reaction process of on-wall ineffective collision, decomposition, inter-molecular ineffective collision and synthesis.

5. Randomly select a molecule or molecules depending on the chosen reaction process.

6. Set the control parameters based on the values of molecule, perform load flow, evaluate the RPL and then compute $P E$.

7. Modify the molecules according to the chosen reaction process.

8. Repeat the steps 4-7 till convergence.

9. The molecule with lowest $P E$ is the optimal solution

10. Stop

\section{SIMULATIONS}

The PM is tested on IEEE 30 bus test system, whose data have been taken from Ref. [2]. The IEEE 30 bus system comprises 6 generators at buses 1, 2, 5, 8, 11 and 13 and four tap changing transformers at lines 6-9, 6-10, 4-12 and 28-27. The adjustable shunt reactive power sources are connected at buses $10,12,17,20,21,23,24$ and 29 for reactive power control. The net power demand of the system is 2.834 per unit on 100 MVA base. The lower and upper voltage limits for both generator and load buses are taken as 0.95 and 1.1 per unit respectively. NR technique [25] is used to carry out the load flow during the optimization process. The optimal solution obtained by the proposed method is compared with those of the GA [11], PSO [14], comprehensive learning PSO (CLPSO) [14], DE [17] and BBO [19] based methods in Table 1. It is very clear from the table that the PM is able to reduce the loss to the lowest value of $\mathbf{0 . 0 4 5 3 5}$ per unit, which leads to $21.97 \%$ loss savings with respect to base case; and is much higher than that of BBO (21.70\%), DE (21.63\%), CLPSO $(21.50 \%)$, PSO $(20.37 \%)$ and GA $(19.99 \%)$. The voltage magnitudes of all load buses of the PM are graphically compared with that of the base-case voltages in Fig.1. It clearly indicates that the PM offer better voltage profile and they lie between the lower and upper limits.

Table 1 Comparison of Results

\begin{tabular}{|c|c|c|c|c|c|c|c|}
\hline $\begin{array}{c}\text { Contr } \\
\text { ol } \\
\begin{array}{c}\text { Varia } \\
\text { bles }\end{array}\end{array}$ & $\begin{array}{c}\text { Base } \\
\text { Case }\end{array}$ & PM & $\begin{array}{c}\text { GA } \\
{[11]}\end{array}$ & $\begin{array}{c}\text { PSO } \\
{[14]}\end{array}$ & $\begin{array}{c}\text { CLPS } \\
\text { O } \\
{[14]}\end{array}$ & $\begin{array}{c}\text { DE } \\
{[17]}\end{array}$ & $\begin{array}{c}\text { BBO } \\
{[19]}\end{array}$ \\
\hline$V_{G 1}$ & 1.05 & $\begin{array}{c}1.10 \\
000\end{array}$ & $\begin{array}{c}1.03 \\
73\end{array}$ & $\begin{array}{c}1.10 \\
000\end{array}$ & $\begin{array}{c}1.10 \\
000\end{array}$ & $\begin{array}{c}1.10 \\
00\end{array}$ & $\begin{array}{c}1.10 \\
000\end{array}$ \\
\hline$V_{G 2}$ & 1.04 & $\begin{array}{c}1.09 \\
409\end{array}$ & $\begin{array}{c}1.03 \\
10\end{array}$ & $\begin{array}{c}1.10 \\
000\end{array}$ & $\begin{array}{c}1.10 \\
000\end{array}$ & $\begin{array}{c}1.09 \\
31\end{array}$ & $\begin{array}{c}1.09 \\
440\end{array}$ \\
\hline
\end{tabular}




\begin{tabular}{|c|c|c|c|c|c|c|c|}
\hline$V_{G 5}$ & 1.01 & $\begin{array}{l}1.07 \\
463\end{array}$ & $\begin{array}{c}1.01 \\
19\end{array}$ & $\begin{array}{l}1.08 \\
670\end{array}$ & $\begin{array}{l}1.07 \\
950\end{array}$ & $\begin{array}{c}1.07 \\
36\end{array}$ & $\begin{array}{l}1.07 \\
490\end{array}$ \\
\hline$V_{G 8}$ & 1.01 & $\begin{array}{l}1.07 \\
605\end{array}$ & $\begin{array}{c}1.01 \\
43\end{array}$ & $\begin{array}{l}1.10 \\
000\end{array}$ & $\begin{array}{l}1.10 \\
000\end{array}$ & $\begin{array}{c}1.07 \\
56\end{array}$ & $\begin{array}{l}1.07 \\
680\end{array}$ \\
\hline$V_{G 11}$ & 1.05 & $\begin{array}{l}1.10 \\
000\end{array}$ & $\begin{array}{c}1.00 \\
71\end{array}$ & $\begin{array}{l}1.10 \\
000\end{array}$ & $\begin{array}{l}1.10 \\
000\end{array}$ & $\begin{array}{c}1.10 \\
00\end{array}$ & $\begin{array}{l}1.09 \\
990\end{array}$ \\
\hline$V_{G 13}$ & 1.05 & $\begin{array}{l}1.10 \\
000\end{array}$ & $\begin{array}{c}1.02 \\
62\end{array}$ & $\begin{array}{l}1.10 \\
000\end{array}$ & $\begin{array}{l}1.10 \\
000\end{array}$ & $\begin{array}{c}1.10 \\
00\end{array}$ & $\begin{array}{l}1.09 \\
990\end{array}$ \\
\hline$T_{6-9}$ & $\begin{array}{c}1.07 \\
8\end{array}$ & $\begin{array}{l}1.02 \\
599\end{array}$ & $\begin{array}{c}1.05 \\
00\end{array}$ & $\begin{array}{l}0.95 \\
870\end{array}$ & $\begin{array}{l}0.91 \\
540\end{array}$ & $\begin{array}{c}1.04 \\
65\end{array}$ & $\begin{array}{l}1.04 \\
350\end{array}$ \\
\hline$T_{6-10}$ & $\begin{array}{c}1.06 \\
9\end{array}$ & $\begin{array}{c}0.90 \\
117\end{array}$ & $\begin{array}{c}1.07 \\
50\end{array}$ & $\begin{array}{l}1.05 \\
430\end{array}$ & $\begin{array}{l}0.90 \\
000\end{array}$ & $\begin{array}{c}0.90 \\
97\end{array}$ & $\begin{array}{l}0.90 \\
117\end{array}$ \\
\hline$T_{4-12}$ & $\begin{array}{c}1.03 \\
2\end{array}$ & $\begin{array}{c}0.96 \\
604\end{array}$ & $\begin{array}{c}1.10 \\
00\end{array}$ & $\begin{array}{l}1.00 \\
240\end{array}$ & $\begin{array}{l}0.90 \\
000\end{array}$ & $\begin{array}{c}0.98 \\
67\end{array}$ & $\begin{array}{l}0.98 \\
244\end{array}$ \\
\hline$T_{28-2}$ & $\begin{array}{c}1.06 \\
8\end{array}$ & $\begin{array}{l}0.96 \\
236\end{array}$ & $\begin{array}{c}0.92 \\
50\end{array}$ & $\begin{array}{r}0.97 \\
550\end{array}$ & $\begin{array}{l}0.93 \\
970\end{array}$ & $\begin{array}{c}0.96 \\
89\end{array}$ & $\begin{array}{c}0.96 \\
918\end{array}$ \\
\hline$Q_{C 10}$ & 0.0 & $\begin{array}{c}0.05 \\
000\end{array}$ & 0 & $\begin{array}{l}0.04 \\
280\end{array}$ & $\begin{array}{l}0.04 \\
927\end{array}$ & $\begin{array}{l}0.05 \\
000\end{array}$ & $\begin{array}{l}0.05 \\
000\end{array}$ \\
\hline$Q_{C 12}$ & 0.0 & $\begin{array}{l}0.04 \\
997\end{array}$ & 0 & $\begin{array}{l}0.05 \\
000\end{array}$ & $\begin{array}{l}0.05 \\
000\end{array}$ & $\begin{array}{l}0.05 \\
000\end{array}$ & $\begin{array}{c}0.04 \\
987\end{array}$ \\
\hline$Q_{C 15}$ & 0.0 & $\begin{array}{c}0.04 \\
999\end{array}$ & $\begin{array}{l}0.02 \\
857\end{array}$ & $\begin{array}{l}0.03 \\
029\end{array}$ & $\begin{array}{l}0.05 \\
000\end{array}$ & $\begin{array}{l}0.05 \\
000\end{array}$ & $\begin{array}{c}0.04 \\
991\end{array}$ \\
\hline$Q_{C 17}$ & 0.0 & $\begin{array}{c}0.05 \\
000\end{array}$ & $\begin{array}{l}0.02 \\
857\end{array}$ & $\begin{array}{l}0.04 \\
037\end{array}$ & $\begin{array}{l}0.05 \\
000\end{array}$ & $\begin{array}{l}0.05 \\
000\end{array}$ & $\begin{array}{c}0.04 \\
997\end{array}$ \\
\hline$Q_{C 20}$ & 0.0 & $\begin{array}{c}0.04 \\
616\end{array}$ & $\begin{array}{l}0.02 \\
857\end{array}$ & $\begin{array}{l}0.02 \\
670\end{array}$ & $\begin{array}{l}0.05 \\
000\end{array}$ & $\begin{array}{l}0.04 \\
406\end{array}$ & $\begin{array}{c}0.04 \\
990\end{array}$ \\
\hline$Q_{C 21}$ & 0.0 & $\begin{array}{c}0.05 \\
000\end{array}$ & $\begin{array}{c}0.08 \\
571\end{array}$ & $\begin{array}{c}0.03 \\
889\end{array}$ & $\begin{array}{l}0.05 \\
000\end{array}$ & $\begin{array}{l}0.05 \\
000\end{array}$ & $\begin{array}{l}0.04 \\
995\end{array}$ \\
\hline$Q_{C 23}$ & 0.0 & $\begin{array}{c}0.03 \\
588\end{array}$ & $\begin{array}{l}0.02 \\
857\end{array}$ & $\begin{array}{l}0.00 \\
000\end{array}$ & $\begin{array}{l}0.05 \\
000\end{array}$ & $\begin{array}{l}0.02 \\
800\end{array}$ & $\begin{array}{l}0.03 \\
875\end{array}$ \\
\hline$Q_{C 24}$ & 0.0 & $\begin{array}{c}0.05 \\
000\end{array}$ & 0 & $\begin{array}{c}0.03 \\
588\end{array}$ & $\begin{array}{l}0.05 \\
000\end{array}$ & $\begin{array}{l}0.05 \\
000\end{array}$ & $\begin{array}{l}0.04 \\
987\end{array}$ \\
\hline$Q_{C 29}$ & 0.0 & $\begin{array}{c}0.01 \\
975\end{array}$ & $\begin{array}{l}0.05 \\
714\end{array}$ & $\begin{array}{l}0.02 \\
842\end{array}$ & $\begin{array}{l}0.05 \\
000\end{array}$ & $\begin{array}{c}0.02 \\
598\end{array}$ & $\begin{array}{c}0.02 \\
910\end{array}$ \\
\hline RPL & $\begin{array}{l}0.05 \\
812\end{array}$ & $\begin{array}{c}\mathbf{0 . 0 4} \\
535\end{array}$ & $\begin{array}{l}0.04 \\
650\end{array}$ & $\begin{array}{l}0.04 \\
628\end{array}$ & $\begin{array}{l}0.04 \\
562\end{array}$ & $\begin{array}{c}0.04 \\
555\end{array}$ & $\begin{array}{c}0.04 \\
551\end{array}$ \\
\hline
\end{tabular}

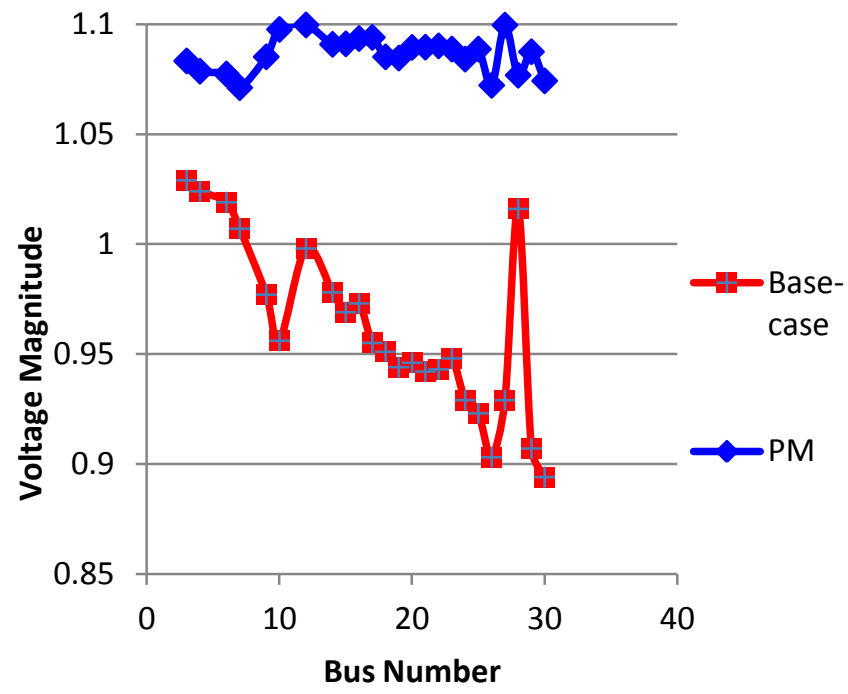

Fig. 1 Plot of voltage profile

\section{CONCLUSION}

CRO is a population based stochastic optimization technique, inspired from the process of chemical reactions, for solving multimodal optimization problems. ORPF is a complex optimization problem determines the values for system control variables that minimize the RPL, while at the same time satisfying various equality and inequality constraints. A CRO is applied to solve ORPF problem. The PM attempts to efficiently search the solution space, avoid the local trap and enhance the convergence. The results of IEEE 30 bus test system project the ability of the PM in obtaining the global best solution. Besides the PM offers a better VP that lies in between the lower and upper limits. The PM for solving ORPF will go a long way in serving as a constructive tool in load dispatch centre.

\section{ACKNOWLEDGEMENT}

The authors gratefully acknowledge the authorities of Annamalai University and Pondicherry Engineering College for the facilities offered to carry out this work.

\section{REFERENCES}

[1] O.Alsac,and B. Scott. (1974). Optimal load flow with steady state security, IEEE Transactions on power Apparatus and systems. PAS: 745-751.

[2] Lee K Y ,Park Y M , Oritz J L. (1985). A united approach to optimal real and reactive power dispatch , IEEE Transactions on power Apparatus and systems. PAS-104:1147-1153.

[3] A.Monticelli, M .V.F Pereira and S. Granville. (1987). Security constrained optimal power flow with post contingency corrective rescheduling, IEEE Transactions on Power Systems, 2(1):175-180.

[4] N Deeb and S.M.Shahidehpur. (1990). Linear reactive power optimization in a large power network using the decomposition approach, IEEE Transactions on power systems, 5(2):428-438.

[5] Hobson. (1980). Network constrained reactive power control using linear programming, IEEE Transactions on power apparatus and systems. PAS -99 (3): 868-877. 
[6] K.Y. Lee, Y.M. Park, and J.L.Oritz. (1984). Fuel-cost minimization for both real and reactive power dispatches, IEE Proceedings C. 131(3): 85-93.

[7] M.K. Mangoli, and K.Y. Lee. (1993). Optimal real and reactive power control using linear programming, Electrical Power System Research. 26(1): 1-10.

[8] J.A. Momoh, S.X. Guo, E.C. Ogbuobiri and R. Adapa. (1994). The quadratic interior point method solving power system optimization problems, IEEE Transactions on Power Systems, 9(3): 1327-1336.

[9] Y.C.Wu, A.S. Debs and R.E.Marsten. (1994). A Direct nonlinear predictor-corrector primal-dual interior point algorithm for optimal power flows, IEEE Transactions on power systems. 9(2): 876-883.

[10] Q. H. Wu, Y. J. Cao and J. Y. Wen. (1998). Optimal reactive power dispatch using an adaptive genetic algorithm, Int. J. Elect. Power Energy Syst., 20(8): 563569 .

[11] S.Durairaj, P.S.Kannan and D.devaraj. (2005). Application of genetic algorithm to optimal reactive power dispatch including voltage stability constraint, Journal of Energy and Environment, 4:63-73.

[12] W. Yan, F. Liu, C.Y. Chung, K.P. Wong. (2006). A hybrid genetic algorithm interior point method for optimal reactive power flow, IEEE Transactions on power. Systems, 21(3): 1163-1169.

[13] L.L. Lai and J.T. Ma. (1997). Application of evolutionary programming to reactive power planningcomparison with nonlinear programming approach, IEEE Transactions on power systems. 12(1):198-206.

[14] K. Mahadevan and P.S. Kannan. (2010). Comprehensive learning Particle Swarm Optimization for Reactive Power Dispatch, Int. J. Applied Soft Computing. 10(2): 641-652.

[15] K. Vaisaka and P. Kanta Rao. (2008). Differential evolution based optimal reactive power dispatch for voltage stability enhancement, Journal of Theoretical and Applied Information Technology, 4(4): 700-709.
[16] Y. Chung, C.H. Liang, K.P. Wong and X.Z. Duan. (2010). Hybrid algorithm for differential evolution and evolutionary programming for optimal reactive power flow, IET Proc. Gen., Trans. \& Dist. 4(1): 84-93.

[17] A.A. Abou El Ela, M.A. Abido and S.R.Spea. (2011). Differential evolution algorithm for optimal reactive power dispatch, Electric Power System research, 81:458464.

[18] B.Dai, W. Chen. (2009). Seeker Optimization Algorithm for Optimal Reactive Power Dispatch, IEEE Transactions Power Systems. 24(3): 1218-31.

[19] Bhattacharya and K.P. Chattopadhyay. (2010). Solution of optimal reactive power flow using biogeographybased optimization, Int. Journal of Electrical and Electronics Engineering. 4(8): 568-576.

[20] Lam AYS, Li VOK.(2010). Chemical-reaction-inspired metaheuristic for optimization, IEEE Trans Evol Comput., 14(3): 381-99.

[21] Lam Albert YS, Li Victor OK, Yu James JQ. (2012). Real-coded chemical reaction optimization, IEEE Trans Evol Comput., 16(3): 339-53.

[22] Kuntal Bhattacharjee, Aniruddha Bhattacharya and Sunita Halder nee Dey. (2014). Solution of economic emission load dispatch problems of power systems by real coded chemical reaction algorithm, Electrical Power and Energy Systems, 59: 176-187.

[23] J. Xu, A. Y. S. Lam, and V. O. K. Li. (2011). Chemical reaction optimization for task scheduling in grid computing, IEEE Trans. Parallel Distrib. Syst., 22(10: $1624-1631$

[24] J. J. Q. Yu, A. Y. S. Lam, and V. O. K. Li. (2011) Evolutionary artificial neural network based on chemical reaction optimization," in Proc. IEEE CEC: 2083-2090.

[25] W.F. Tinney and C.E. Hart. (1967). Power flow solution by Newton's method, IEEE Transaction on Power Apparatus And Systems PAS-86(11): 1449-1460. 